\title{
The Benefits of Simulations as Remote Exercises during the COVID-19 Pandemic - An Enzyme Kinetics Case Study
}

Andrew F. Worrall, ${ }^{a}$ Patrick E. Bergstrom Mann, ${ }^{a}$ Damion Young, ${ }^{b}$ Mark R. Wormald, ${ }^{c}$ Samuel T. Cahill, ${ }^{a}$ Malcolm I. Stewart*,a

a Chemistry Teaching Laboratory, Department of Chemistry, University of Oxford, South Parks Road, Oxford, OX1 3PS, United Kingdom

b Sherrington Building, Department of Physiology, Anatomy and Genetics, University of Oxford, Sherrington Road, Oxford, OX1 3PT, United Kingdom

c Oxford Glycobiology Institute, Department of Biochemistry, University of Oxford, South Parks Road, Oxford, OX1 3QU, United Kingdom

\begin{abstract}
Teaching practical chemistry skills remotely is not a task that would have been high on the agenda only a few months ago. However, in light of the COVID-19 pandemic, students around the world are having to work from home, and the chemistry education community forced to adapt to the new circumstances. In response, we discuss the use of simulations in place of practical laboratory work, with emphasis on the development of students' experimental design skills. The simulation of Michaelis-Menten enzyme kinetics is given as an example exercise, which other instructors could implement with immediate effect.
\end{abstract}

\section{GRAPHICAL ABSTRACT}

\begin{tabular}{|c|c|c|c|}
\hline \multirow[t]{2}{*}{ Samples: } & \multirow{2}{*}{$\begin{array}{l}\text { Working } \\
\text { vol: }\end{array}$} & \multirow{2}{*}{$\begin{array}{l}\text { Time: } \\
\text { 9:00 }\end{array}$} & \multirow{3}{*}{$\begin{array}{l}\text { Hints } \\
\text { You need to set up your } \\
\text { apparatus - click the 'Setup } \\
\text { apparatus' button } \\
\text { You have no defrosted } \\
\text { enzyme - click a sample to } \\
\text { defrost }\end{array}$} \\
\hline & & & \\
\hline & $0 \mu \mathrm{l}$ & $\begin{array}{l}\text { Good } \\
\text { morning }\end{array}$ & \\
\hline
\end{tabular}

\section{KEYWORDS}

Second-Year Undergraduate, Upper-Division Undergraduate, Biochemistry, Interdisciplinary/Multidisciplinary, Computer-Based Learning, Distance Learning/Self Instruction, Inquiry-Based/Discovery Learning, Internet/Web-Based Learning, Kinetics, Enzymes 


\section{INTRODUCTION}

Towards the end of March 2020 our university went into "lockdown", prompted by the UK Government's attempts to control the spread of COVID-19. It soon became clear that the disruption would significantly impact the delivery of a traditional wet-lab chemistry course for the foreseeable future, and computer-based exercises would be needed to substitute. In response, regular meetings were set up for the practical chemistry community to discuss the challenges faced, and to share ideas for suitable remote exercises. ${ }^{1}$ These DryLabs20 meetings also raised a number of concerns among the community. One concern in particular was that a lot of the exercises being carried out were grounded in computational or physical chemistry, as these most readily lend themselves to remote work. As a result, a disproportionate amount of time would be spent by students on these exercises and not on other important topics, such as synthetic chemistry, which are undoubtedly more difficult to implement as computer-based exercises.

One approach to the provision of practical chemistry work has been to remove the practical element from existing experiments, give students the data, and have them analyze it as they normally would. This, however, does not increase the variety of activities that students are carrying out remotely, and even decreases the number of experiments available to students once they are back in the lab.

We feel simulations are an excellent way to best tackle the problem of remote work as they allow students to collect and analyze their own data. They can also have more relevance to the work that students have done previously in the lab, building on core skills and knowledge. The benefits of simulations in teaching chemistry are nothing new, and have been reported on as complementary to practical chemistry exercises. ${ }^{2,3}$ To be of most use during the COVID-19 pandemic, good simulations should:

- $\quad$ Build upon the theory introduced in a wet-lab session.

- Encourage students to plan their experiments in order to best make use of available resources, and maximize data quality.

- Be capable of being run remotely by all students.

- Hinder student collusion by providing different parameters to each student. 
A further requirement in this time of need is that exercises need to be deployable on a short timescale. Simulations that address all of the key points above can take years of development, which does not lend itself to the rapidly changing situation we find ourselves in. As such, it is important for the community to identify suitable resources that may be shared among institutions to benefit as many students as possible while they are away from the laboratory. Here we present a case study on one such resource, an enzyme kinetics simulation that we have employed to build on students' previous experience of working with enzymes in the laboratory.

\section{ENZYME KINETICS SIMULATION CASE STUDY}

\section{Background}

In normal times, we offer a standard, wet-lab exploration of the kinetics of an enzymatic reaction, which takes place in the second year of a four-year, undergraduate M.Chem. degree program. The session introduces the students to a coupled assay, in which they indirectly observe the oxidation of D-glucose by glucose oxidase (GOx) through a subsequent reaction catalyzed by horseradish peroxidase, based on previously reported procedures. ${ }^{4-7}$ The students follow precise instructions to reproduce predetermined data, allowing them to determine the $\mathrm{K}_{\mathrm{m}}$ and $\mathrm{V}_{\max }$ parameters for the GOx enzyme. In this way they are introduced to the basics of Michaelis-Menten kinetics and gain experience of working with enzymes.

By its very nature, and because of the previous lack of biochemical experience of the students, this procedure has a large "cookbook" component to it. The parameters of the exercise, $\mathrm{pH}$, temperature, enzyme concentration, etc., are pre-set to ensure the students obtain interpretable results within the six-hour laboratory session. This approach also cuts down on the inevitable waste that occurs when relatively expensive enzymes are placed into the hands of inexperienced experimenters. We wanted to find a follow-up exercise that allowed the students to concentrate on how to plan the determination of Michaelis-Menten kinetic parameters, while removing the cognitive load of dealing with an unfamiliar experimental procedure. To this end, a flexible, well-programed, virtual simulation was sought.

The enzlab Simulation

There are a number of resources online that simulate the determination of kinetic parameters for enzymes through a process of experimental design, and generally adhere to the requirements outlined 
above. However, some are restricted to a single enzyme with pre-determined kinetic parameters, ${ }^{8}$ while others explore numerous enzymes but do not provide enough variety to avoid collusion. ${ }^{9}$ Two of the authors (Damion Young and Mark Wormald) had previously developed an enzyme kinetics simulation, enzlab, that actively addresses the issue of student collusion. ${ }^{10}$ This freely accessible, web-based package was based on a version of enzymeLAB created by John Garratt and colleagues at the University of York. ${ }^{2,11}$ The demise of MS DOS support in modern versions of Windows required a complete rewrite of enzymeLAB. This gave the authors an opportunity to create a web-based (Javascript - AngularJS) application that was not only more user-friendly, but also more accurate and realistic than the original.

The enzlab simulation generates a virtual enzyme that is unique to the student undertaking the task: it has the capacity to generate $1.2 \times 10^{6}$ different enzymes, such that the chances of any two students being set the same task is remote. The student is provided with a code by the simulation that, when submitted with the report for assessment, allows the assessor to see what values of $K_{m}$ and specific activity should have been measured. In this way, students may collaborate on the best method of approach but must obtain and interpret their own data. Each enzyme is also designed to display activity that depends upon two amino acid side chains. The $\mathrm{pK}_{\mathrm{a}}$ values of these sidechains can be determined by the student, together with the effect that they have on $\mathrm{K}_{\mathrm{m}}$ and/or $\mathrm{V}_{\max }$ (or indeed, neither). This gives the students a range of enzymes that have activity versus $\mathrm{pH}$ profiles that are classic, bell-curves or show dependence on one $\mathrm{pK}_{\mathrm{a}}$ only.

The experimental design aspects are at the heart of the simulation. Figure 1 shows the enzlab interface and the range of functionality available. In this virtual space, the student is given a fixed quantity of enzyme, frozen in six vials of $500 \mu 1$, and six virtual days within which to carry out their experiments. The student has to plan their working day, setting up the experiment, taking breaks, and running assays. The whole simulation runs in a day and each activity takes up a certain amount of time, neither of which is real time. There is experimental error built into the results that the simulation generates, and this increases if the student has to work "late" to finish the experiments. The objectives of the virtual lab are: 
- To determine the optimum $\mathrm{pH}$ for the enzyme - this will involve deciding how much enzyme to use in each assay and what range of $\mathrm{pH}$ to investigate.

- To determine $\mathrm{K}_{\mathrm{m}}$ and the specific activity at the optimal $\mathrm{pH}$ - this will involve deciding what range of substrate concentrations to use. Students also are required to investigate the error in these values by doing repeat assays.

- To determine the $\mathrm{pH}$ dependence of $\mathrm{K}_{\mathrm{m}}$ and $\mathrm{V}_{\max }$. behavior that is demonstrated. We decided not to pursue this aspect of the simulation with our second-year chemists, although it would make an excellent addition for further investigation, or if delivering an exercise for biochemistry students.

\section{Michaelis-Menten Enzyme Kinetics}

\begin{tabular}{l}
$\begin{array}{l}\text { Control Panel } \\
\text { [Substrate] (mM) }\end{array}$ \\
\hline [Inhibitor] (mM) \\
\hline
\end{tabular}
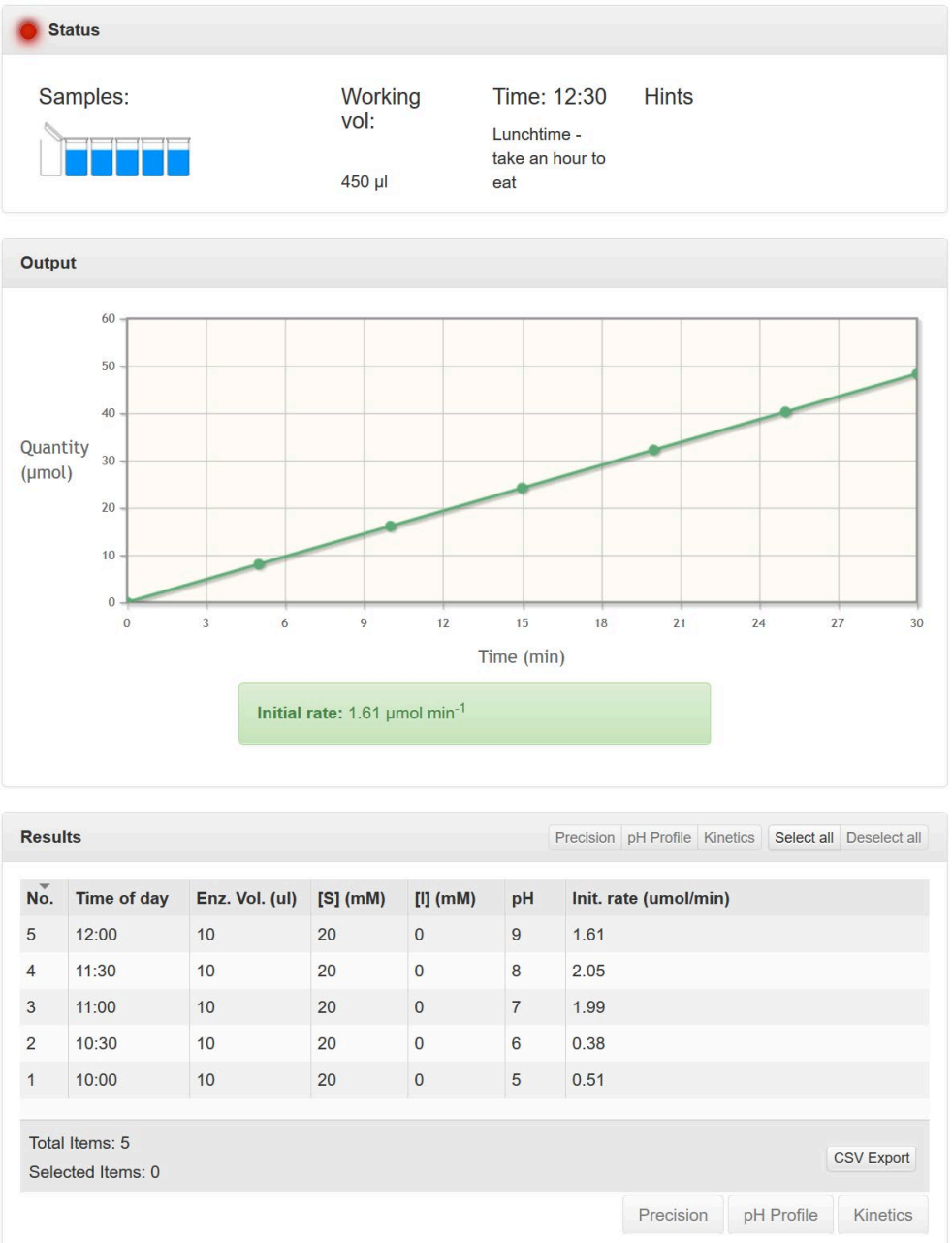
Figure 1. An example of the enzlab interface. Here, five measurements have been performed and the user must use up an hour for lunch before continuing with the experiments. The most recent rate measurement is displayed both as a graph and a numerical value. Each result line may be selected for plotting using the Precision, pH Profile, and Kinetics preset buttons as required.

Students are given an approximate specific activity of their enzyme sample in mmol min-1 $\mathrm{mg}^{-1}$ for a given substrate concentration and $\mathrm{pH}$ 7. They are also given the concentration of the enzyme in $\mathrm{mg} \mathrm{mL}-1$, and are told that the assay that has been developed gives useful results in the range 0.2-10 $\mu \mathrm{mol} \mathrm{min} \mathrm{m}^{-1}$. From this information alone, they are expected to plan and experiment to achieve their objectives. If they run out of enzyme, they need to start again but this will generate a whole new enzyme - previous data is lost but the experience of experimental design is retained. In this way, they soon learn which decisions are key in planning the experiments.

The simulation generates lines of data that show Time of Day, Enzyme Volume, Substrate Concentration, $\mathrm{pH}$, and Initial Rate of reaction. This data can be processed in different ways, as required by the student. It can be exported as a comma separated values (.csv) list for manipulation in spreadsheet software, or handled directly in the simulation. Our second-year students are familiar with the linearizing plots of Eadie-Hofstee and Hanes-Woolf from the earlier laboratory session, however, in that lab, they are also introduced to the merits of non-linear curve fitting. The simulation has a built-in curve-fitting tool, developed from original code by John C. Pezzullo, ${ }^{12}$ that they can use to generate values for $\mathrm{K}_{\mathrm{m}}$ and $\mathrm{V}_{\max }$ (Figure 2). Having produced and analyzed their data, the students are asked to produce a full written report on their endeavors, which is submitted for assessment via Canvas, the university Virtual Learning Environment. From their data, they should be able to suggest which amino acid side chain(s) are responsible for the activity/pH profile they have determined and, further, should be able to suggest whether the side chain is involved in catalysis, substrate binding or both. 


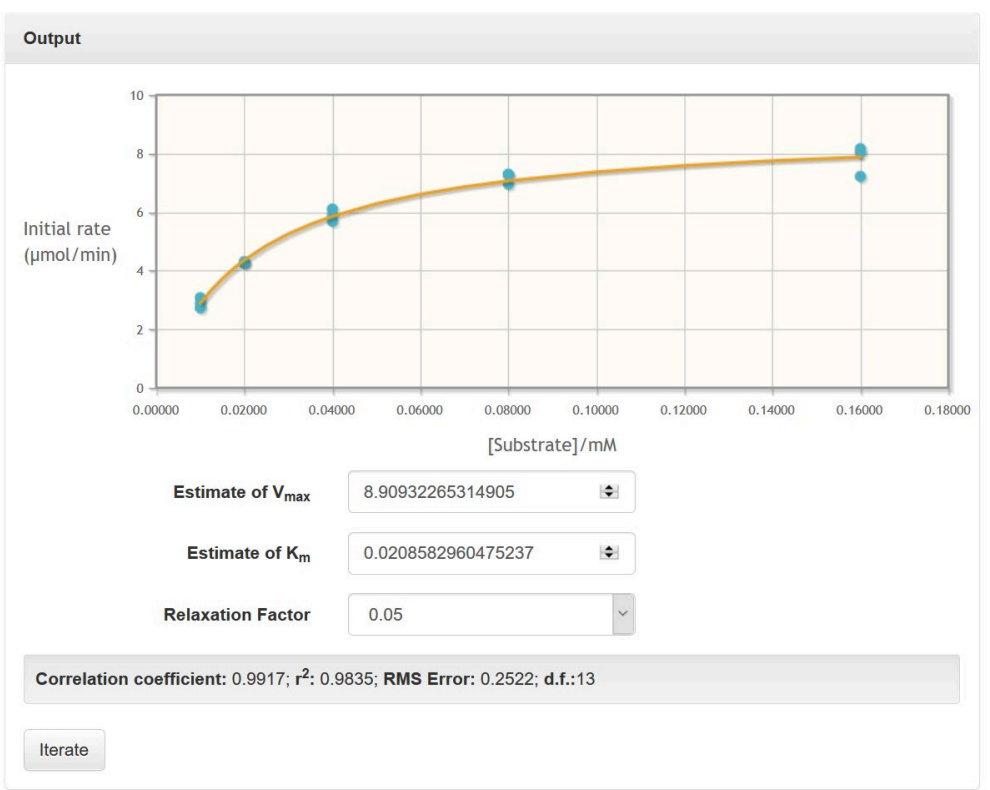

Figure 2. An example of the built-in curve fitting tool used to extract values of $V_{\max }$ and $\mathrm{K}_{\mathrm{m}}$ from a data set of three repeat measurements of the initial rate, at five different substrate concentrations.

Online Interaction with Students

While undertaking the exercise, students are able to email an advisor who can answer any queries that might arise. The simple, web-based nature of the simulation has meant that these questions have, so far, never been technological in nature: it appears to run without issue on a variety of platforms, including tablets and mobile phones. Development of a similar simulation using a proprietary e-learning platform was reported with a number of technological problems. ${ }^{13}$ These ranged from slow loading times and software bugs, to incompatible browsers and devices, particularly iPads and iPhones. The work highlights the problem with paid or proprietary simulations that often hinder accessibility. It is our experience that while they might offer enhanced functionality, this is often at the expense of support on all relevant platforms. Importantly, the enzlab exercise does not require students to download any software, which has proved somewhat of an impediment to the smooth running of other remote exercises that we have implemented. To consider the needs of students who might be restricted to incompatible devices when they are away from university, the option to use a university computer via remote access was established, although this has not yet been necessary for the enzlab simulation. 
The issues that have cropped up have been linked to the students' chemistry-based understanding of enzymes and how they work. In particular, at the time of writing and having run the lab for four weeks, the most common misconception was linked to students interpreting a bell-shaped activity versus $\mathrm{pH}$ plot as being linked to the need for amino acids to be in their zwitterionic form. They had and cannot involve the $-\mathrm{NH}_{2}$ or $-\mathrm{COOH}$ groups in the free amino acid. This was linked to their lack of understanding of polypeptide structure and it is clear we need to update the laboratory manual to reflect this.

\section{Student Feedback}

Participating students were asked for feedback on the delivery on of the exercise, the success of the intended aims, and its usefulness as a follow-up to the previous wet-lab activity. The questionnaire is included for reference as part of the Supporting Information. On the whole, students indicated that the exercise was a welcome change to other remote activities as it was the one that most related to a "realworld experiment". Students agreed that the simulation had achieved its intended aims of developing experimental design skills:

Overall I found the practical very enjoyable and rewarding. I think having to plan an experiment can be quite a daunting task and I definitely feel this practical has improved my confidence towards doing so in the future.

Removal of the cognitive load associated with carrying out precise measurements in a laboratory setting resonated with the students, allowing them to focus on the experimental design aspects and build on their confidence in this area.

I attained a fuller understanding of what I was doing and what I was looking for in my results as I wasn't just following a lab manual.

It was also good to get a feel of how to plan an experiment where there were no real-world consequences when mistakes were made - [the simulation] really helped to refine experimental plan and technique.

The in-built error in the measurements also proved to be a useful learning experience. The tendency of students to leave the consideration of error analysis until after they have completed a practical is a habit that needs to be discouraged if the students are to go on to successfully plan their own experiments. ${ }^{14}$ 
Observing that the standard deviation of such experiments is surprisingly large helped me to appreciate the importance of parallel measurements, and the statistical analysis of your data. It was a very useful experiment regarding the guided self-teaching of the data analysis by trial and error.

\section{DISCUSSION}

The simulation has so far proved to be a successful addition to the exercises available to students to work on at home. Student feedback has been encouraging, suggesting that the simulation both aided in students' understanding of the importance of experimental design, and provided a refreshing change to the coding-based exercises they have otherwise been undertaking. Having completed the previous enzyme kinetics wet-lab, the students' have a framework on which they can base their approach to the simulation, avoiding the problems of overwhelming cognitive load that can otherwise hinder unguided experimental design tasks. ${ }^{15} \mathrm{~A}$ similar approach to the teaching of experimental design through integration with a practical exercise has also recently reported success. ${ }^{16}$ As testament to the simulation's efficacy, it is our intention to keep the exercise as part of our practical chemistry course, once the need for remote work has passed.

An important aspect of the exercise was the avoidance of student collusion - an ever-present concern that has only become more prevalent with the increase in computer-based activities carried out away from the university. ${ }^{17}$ The ease of online communication and the unsupervised nature of remote work requires that exercises must be designed to effectively minimize the chances of students sharing answers to virtual laboratory tasks. Primarily, the aim was to encourage students to engage with the exercises as they would if they were present in a physical laboratory, which can be severely undermined if the answers are readily available. This is particularly problematic in STEM subjects where there is often a single correct answer, making collusion more difficult to detect. ${ }^{18}$ As such, having such a large number of possible enzymes available in the enzlab simulation ensures that students engage with the exercise and contact staff when they are stuck, rather than sourcing answers from their peers.

In summary, we were looking for an activity that would teach aspects of experimental design, to follow on from a traditional, recipe-lead lab session exploring enzyme kinetics. This had to be easy enough for a cohort of 180 , second-year chemistry undergraduates to run remotely due to a pre- 
planned building closure and the emergence of COVID-19. It had to be scientifically sound, sufficiently flexible for all students to carry out a different iteration of the task, and generate data that could be easily manipulated. We have found that enzlab fulfils these requirements and has provided our students with the opportunity to investigate aspects of experimental design when they are away from the lab. Crucially, the resource was readily available for use and could be implemented at short notice to ensure students remained engaged with aspects of practical chemistry during the pandemic.

Furthermore, we feel the enzlab simulation should serve as a template for the continued development of robust and widely accessible virtual laboratory exercises while the disruption from the COVID-19 pandemic continues.

\section{ASSOCIATED CONTENT}

Supporting Information

A guide for the interpretation of the enzyme codes into kinetic parameters for the enzlab simulation may be obtained by emailing the authors. The Supporting Information is available on the ACS Publications website at DOI: 10.1021/acs.jchemed.XXXXXXX.

Exercise Instructions (DOCX)

Demonstrator Notes (DOCX)

Student Feedback Questionnaire (DOCX)

\section{AUTHOR INFORMATION}

\section{Corresponding Author}

*E-mail: malcolm.stewart@chem.ox.ac.uk

\section{ACKNOWLEDGMENTS}

We would like to thank David Harris for his contribution to the enzlab simulation.

\section{REFERENCES}

1. Further Information about the DryLabs20 Meetings May Be Obtained by Contacting the Authors.

2. Garratt, J. Virtual Investigations: Ways to Accelerate Experience. Univ. Chem. Educ. 1997, 1 (1), $19-27$.

3. Aikens, D. A.; Bailey, R. A.; Bunce, S. C.; Clark, G. M.; Clark, H. M.; Dondes, S.; Hepfinger, N. F.; Strong, R. L. Report of the Conference on Laboratory Instruction in Chemistry. J. Chem. Educ. 1975, 52 (1), 27. 
4. Toren, E. C. Determination of Glucose: A Kinetics Experiment for the Analytical Course. J. Chem. Educ. 1967, 44 (3), 172-174.

5. Bateman, R. C.; Evans, J. A. Using the Glucose Oxidase/Peroxidase System in Enzyme Kinetics. J. Chem. Educ. 1995, 72 (12), 240-241.

6. Kroa, B. A.; Yourey, T. Factors Affecting Reaction Kinetics of Glucose Oxidase. J. Chem. Educ. 2002, 79 (1), 74 .

7. Vasilarou, A. M. G.; Georgiou, C. A. Enzymatic Spectrophotometric Reaction Rate Determination of Glucose in Fruit Drinks and Carbonated Beverages. J. Chem. Educ. 2000, 77 (10), 13271329.

8. Darkow, J. Lactase Enzyme Activity with Data Analysis https://sites.google.com/site/biologydarkow/lactase-enzyme-simulation (accessed May 2020).

9. Bender, D. A. The virtual laboratory: Enzyme assay https://www.ucl.ac.uk/ ucbcdab/enzass/enzymass.htm (accessed May 2020).

10. Young, D.; Wormald, M.; Harris, D. Michaelis-Menten Enzyme Kinetics https://learntech.imsu.ox.ac.uk/enzlab/ (accessed May 2020).

11. Garratt, J.; Tomlinson, J.; Clow, D. Simulating Biochemistry: The eLABorate Project https://openjournals.library.sydney.edu.au/index.php/CAL/article/view/6139 (accessed Jun 2020).

12. Pezzullo, J. C. Web Pages that Perform Statistical Calculations! https://statpages.info/ (accessed May 2020).

13. Booth, C.; Cheluvappa, R.; Bellinson, Z.; Maguire, D.; Zimitat, C.; Abraham, J.; Eri, R. Empirical Evaluation of a Virtual Laboratory Approach to Teach Lactate Dehydrogenase Enzyme Kinetics. Ann. Med. Surg. 2016, 8, 6-13.

14. Garratt, J.; Tomlinson, J. Experimental Design - Can It Be Taught or Learned? Univ. Chem. Educ. 2001, 5 (2), 74-79.

15. Morgan, K.; Brooks, D. W. Investigating a Method of Scaffolding Student-Designed Experiments. J. Sci. Educ. Technol. 2012, 21 (4), 513-522.

16. Seery, M. K.; Jones, A. B.; Kew, W.; Mein, T. Unfinished Recipes: Structuring Upper-Division Laboratory Work to Scaffold Experimental Design Skills. J. Chem. Educ. 2019, 96 (1), 53-59.

17. Sutton, A.; Taylor, D. Confusion about Collusion: Working Together and Academic Integrity. Assess. Eval. High. Educ. 2011, 36 (7), 831-841.

18. Barrett, R.; Cox, A. L. "At Least They're Learning Something”: The Hazy Line between Collaboration and Collusion. Assess. Eval. High. Educ. 2005, 30 (2), 107-122. 